\title{
NOTE: \\ Effect of Microwave Pretreatment on Gaharu Essential Oil Using Hydrodistillation Method
}

\author{
Nurhaslina Che Radzi ${ }^{*}$ and Filzah Anati Kasim \\ Faculty of Chemical Engineering, Universiti Teknologi MARA, 40450 Shah Alam, Selangor, Malaysia
}

\author{
*Corresponding author: \\ email:nurhaslina483@uitm.edu.my
}

Received: January 1, 2019

Accepted: December 29, 2019

DOI: $10.22146 /$ ijc. 43191

\begin{abstract}
Gaharu wood produces an expensive essential oil due to its fragrance and chemical compounds. Normally, the black color wood is used for the extraction of oil because it contains high resin. However, the cost of this resinous wood is very expensive. Therefore, in this study, the raw material with low resin content (identified by the white color of the wood) will be used for the extraction of oil. However, hydrodistillation alone will not produce satisfactory volume. Thus, pretreatment is needed to enhance the amount of essential oil. This paper aims to investigate the effect of microwave pretreatment on gaharu essential oil extraction using the hydrodistillation method for the lower grade wood. The gaharu wood was pre-treated with microwave irradiation power of $800 \mathrm{~kW}$ at three different durations which were 1, 2 and 3 min. Later, extraction was performed using the hydrodistillation method for $30 \mathrm{~h}$. The chemical composition of the oil was analyzed using gas chromatography-mass spectrometry (GCMS). The results show that microwave pretreatment produced higher yield (0.0379wt.\%) of gaharu essential oil compared to the extraction of the non-pretreated wood $(0.0286 w t . \%)$ in which the increase was $24.55 \%$. The three minutes pretreatment time produced the largest amount of oil (0.0877 wt.\%). The outcomes of this study indicated the increase of chemical components of gaharu essential oils such as (+)-Epi-bicyclosesquiphellandrene, gurjunene, $\alpha$-farnese, estragole, guaiene, valencene, spathulenol, $\alpha$-cubebene and (-)-Spathulenol in the extraction of the pre-treated wood compared to the non-pretreated one.
\end{abstract}

Keywords: gaharu; microwave; hydrodistillation; essential oil; gas chromatography mass spectrometry (GCMS)

\section{- INTRODUCTION}

Gaharu is a resinous heartwood tree that belongs to the Thymelaeceae family. A few other names for Gaharu are agar, agarwood, eaglewood, and aloeswood. Gaharu types of Aquilaria malaccensis, Aquilaria crassna, Aquilaria sinensis and Aquilaria filarial are famously exploited worldwide [1]. Aquilaria malaccensis usually live and are cultivated in the habitat with a temperature between 22 to $24^{\circ} \mathrm{C}$ and at the altitude range of 0 to $850 \mathrm{~m}$, which is suitable to Malaysia's climate [2].

Essential oils can be obtained from the roots, stems, leaves, stalks, fruits, and flowers of plants and distilled from resins [3]. However, the uniqueness of gaharu comes from the development of the resinous gaharu in a natural process due to its response to the parasitic ascomycetous mold, Phialophora parasitica, a dematiaceous (darkwalled) fungus. The sweet-smelling pitch is normally formed in the bark, roots and the heartwood of the trees. Gaharu is a timeless tree that can be used in fragrance and perfumery products, medical purposes, religious rituals, etc. [4]. As early as the thirteenth century, gaharu has been playing an important role in lots of practices related to Buddhism, Hinduism, Islam, Christianity and Judaism for cultural, religious, and medical purposes. In the Old Testament, gaharu was used as perfume, while in Ayurvedic, Tibetan and East Asian literature, gaharu was mentioned as a medicinal medium [5]. Gaharu also plays a significant part in Buddhist religious ceremonies, 
where gaharu is burned around the Buddha statue in their rituals [2].

Nowadays, since the value of gaharu is increasing, researchers and entrepreneurs are inspired to find the best method and technique of extraction to get the optimum essential oil yield while reducing the cost and energy. The effectiveness of the extraction process from a natural plant is affected by several factors such as polarity and concentration of the solvent, solvent to feed ratio, extraction process time and thermal degradation as well as valid sample preparation to avoid the degradation of the plant extract. The price of essential oil from gaharu is solely depend on its quality which is graded by human experience from the old-age practice of each country [6].

Various extraction methods can be used to produce essential oils. Currently, hydrodistillation, steam distillation, water distillation, and solvent extraction are commonly used to extract essential oil from plants; however, hydrodistillation method is one of the simplest, oldest and most primitive processes for obtaining essential oil from plants and it is mostly used by small scale manufacturers of essential oils, but the process is slow because it takes 3-5 days to distillate, thus making it uneconomical due to the high consumption of fuel/gas [7].

From the author's view, there are two main constraints in this area. First, a direct heating source using a hydrodistillation extraction method will destroy a certain sensitive essential oil compound [8]. However, the process to change the hydrodistillation technique with other methods will be an issue to the practices of conventional industries due to additional costs that need to be invested. Therefore, an alternative approach combining conventional technology (hydrodistillation) with additional lower cost equipment may be an option. The hydrodistillation method aided with microwave pretreatment will help improve the efficiency of extraction of the gaharu essential oil by reducing the processing time, saving energy and cost as well as increasing extraction yield and quality of the essential oil produced. All this is possible because microwave radiation will induce the rupture of the cell membrane and improve its porosity, thus causing the oil to transfer better [8-9].
The second issue is the high price of the gaharu itself. The Grade A gaharu reaches as high as RM 16,000 per kilogram in Malaysia depending on the quality of the essential oil [8]. However, in one whole tree of gaharu, usually only the black woody part that represents the high quality resin, would be used, leaving the white woody part as waste. Therefore in this study, a method is proposed to fully utilize this waste by extracting the essential oil and study its chemical properties. Thus, the objectives of this research are to investigate the effect of microwave pretreatment on essential oil yield via the hydrodistillation process and the effect of microwave on the chemical composition of oil extract from lower grade gaharu.

\section{- EXPERIMENTAL SECTION}

\section{Materials}

Gaharu stembark (A. malaccencis) grade $\mathrm{C}$ was collected and purchased from a plantation in Kuala Krai, Kelantan, Malaysia. Then the sample was ground using a crusher (model: SLM-20PI/D) to obtain the size of $0.5 \mathrm{~cm}$ and afterwards stored into zip plastic bags. Tap water was used to soak the gaharu sample.

\section{Procedure}

\section{Microwave pretreatment}

Two kilograms $(2 \mathrm{~kg})$ of the ground gaharu was prepared for each sample. The gaharu samples were placed on a $16 \mathrm{~cm}$ microwave plate $(40.0 \mathrm{~g}$ on each plate). The microwave (Model R-397J(S), SHARP Malaysia) ran with the constant operation power of $800 \mathrm{~kW}$ and the processing time for this microwave pretreatment was set in three different durations of 1,2 and $3 \mathrm{~min}$. Gaharu samples were then cooled under ambient temperature.

\section{Hydrodistillation}

Two kilograms ( $2 \mathrm{~kg})$ of gaharu with pretreatment and without pretreatment process was soaked indifferent containers, each containing $9 \mathrm{~L}$ of water for $72 \mathrm{~h}$ at room temperature. Then, the hydrodistillation process was carried out with the processing time set at 30 and $47 \mathrm{~h}$. The obtained gaharu essential oil was collected and the existing solvent was removed using the 
rotary evaporator. Essential oil yield (wt.\%) can be calculated using Eq. (1).

Essental oil yield $($ wt. $\%)=\frac{\text { Mass of oil extracted }(\mathrm{g})}{\text { Mass of sample }(\mathrm{g})} \times 100 \%$

\section{Gas chromatography mass spectrometry (GCMS)}

The analysis of gaharu essential oil chemical compounds was carried out using GCMS. This analysis was required to identify the active compounds in the gaharu essential oil. Table 1 shows the summarized setting conditions of the GCMS analysis [10]. Fig. 1 demonstrate the flow of the extraction process and the GCMS equipment.

Table 1. Condition for GCMS analysis

\begin{tabular}{ll}
\hline Component & Condition \\
\hline Ionization voltage & $70 \mathrm{eV}$ \\
Gas flow & $2 \mathrm{~mL} / \mathrm{min}$ \\
Split ratio & $1: 50$ \\
Injection volume & $1 \mu \mathrm{L}$ \\
Oven program & $80^{\circ} \mathrm{C}$ for $2 \mathrm{~min}$, then $10^{\circ} \mathrm{C} / \mathrm{min}$ \\
& heating rate to $250^{\circ} \mathrm{C}$ for $10 \mathrm{~min}$ \\
Carrier gas & Helium \\
Interface temperature & $250^{\circ} \mathrm{C}$ \\
\hline
\end{tabular}

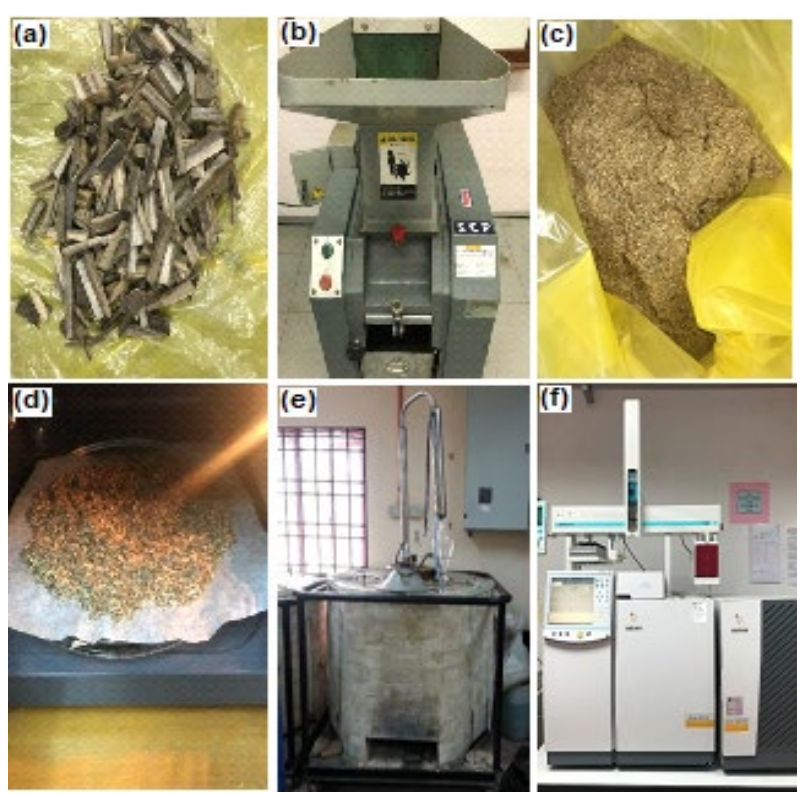

Fig 1. Extraction Process flow and GCMS analysis of gaharu essential oil, (a) Coarse raw material, (b) Grinding process using crusher, (c) Ground gaharu, (d) Microwave pretreatment, (e) Hydrodistillation process, (f) Analysis using GC-MS

\section{- RESULTS AND DISCUSSION}

\section{The Effect of Microwave Pretreatment on Essential Oil Yield via Hydrodistillation Process}

Microwave pretreatment provides the potential to induce stress reactions in the plant system. Fig. 2 shows the yield percentages of gaharu extracted oil at $30 \mathrm{~h}$ of hydrodistillation with and without microwave pretreatment for the duration of 1,2 and $3 \mathrm{~min}$. Results show that the pretreated gaharu with 3 min exposure to microwave produced a higher oil yield which was 0.0877 wt.\% compared to the non-pretreated sample which only produced 0.0286 wt.\%. For the treated gaharu, microwave pretreatment at $3 \mathrm{~min}$ had the highest percentage of extracted oil yield $(0.0877 \%)$ followed by $2 \mathrm{~min}(0.0779 \%)$ and $1 \mathrm{~min}(0.0379 \%)$ of microwave pretreatment. This result is in line with a previous research [9] which stated that through microwave pretreatment, bioactive compounds can penetrate out from the cell wall and produce greater amounts of oil. Similar studies by other researchers [8] revealed that the extracted oil yield from hazelnut seeds increased after the application of microwave treatment before conducting extraction.

The increase in the extracted oil yield was due to the modification of the cellular walls which resulted in greater porosity. The electromagnetic wave produced by

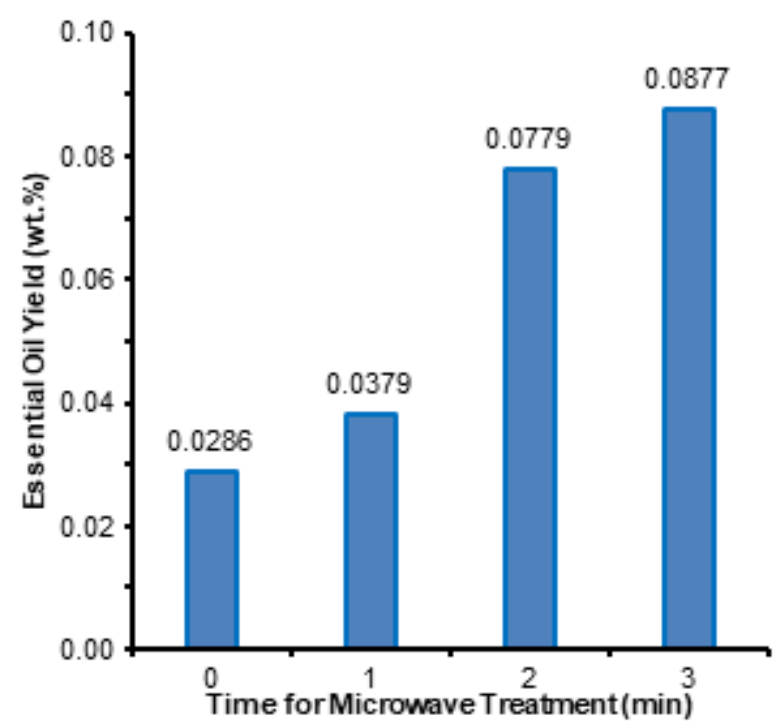

Fig 2. Effect of pretreatment on extracted oil yield weight percentage 
microwave at high frequency can cause penetration to the plant and reach the inside of the materials and rupture the cell wall, thus causing damage to accelerate and simplify the cell wall and bring the gaharu oil out of the material [11]. Rupture of cells is essential before the extraction of the desired compound of plant tissue. Pretreatment of material by blanching and microwave treatment can influence product quality [12]. Thus, a higher quality of essential oil can be obtained with lower time and fuel consumption by performing microwave pretreatment. The results obtained was also in agreement with previous work that stated that the yield of essential oil of gaharu increased after 5-day distillation compared to 1-day distillation [13].

In addition, it can also be observed that the production of oil increased as the exposure time to microwave during pretreatment increased. This trend is found to be similar to the results obtained by a previous researcher which had proven that oil extraction yield can be increased by prolonging microwave treatment time [14]. This can be related to the mechanism of the heating source, which is the microwave that provides changes on the microstructure of the sample. The higher number of oil yield resulted from the interaction of the sample molecule with an electromagnetic field produced from microwave treatment that can cause energy delivery to the plant sample [8].

\section{Chemical Composition of Gaharu Essential Oil}

The list of the chemical composition of the oil obtained from the extraction of gaharu samples, with and without microwave pretreatment, are presented in Table 2. According to the results, the sample with a duration of 3 min microwave pretreatment showed a higher number of volatile components (64 compounds) compared to the non-pretreated samples (61 compounds). Similar trends have been observed by previous researchers [15-16] which highlighted that volatile components of gaharu essential oil depended on its species, pretreatment and extraction method. The research done by using microwave pretreatment on seed had supported the finding of a greater number of bioactive compounds that may have penetrated out from the grounded gaharu to the produced oil [15,17-18]. Conditioning of gaharu at $3 \mathrm{~min}$ microwave pretreatment and $30 \mathrm{~h}$ of hydrodistillation processing time increased the amount of gurjunene, $\alpha$ Farnesene, estragole, guaiene, verrucarol, valencene, $\alpha-$ cargophyllene, spathulenol and a-cubebene in the essential oil yield.

As can be seen in Table 2, 21 active compounds were detected in the essential oil obtained from the nonpretreated sample, from a total of 61 chemical compounds with purity higher than $7 \%$. The major compounds for non-pretreated gaharu are $\alpha$ panasinsene, gurjunene (1,4-dimethyl-1,2,3,3a,4,5,6,7octahydro-7-azulene) and $\alpha$-farnesene. The compound $\alpha$-panasinsene is known as a sesquiterpenoid that can be found in tea and ginseng oil. Meanwhile, gurjunene, spathulenol, verrucarol, spathulenol and guaiene were found to be the major components of oil extracted from the sample with $3 \mathrm{~min}$ microwave pretreatment. The results showed that the pretreated and non-pretreated samples produced oil that had a similar chemical composition where gurjenene is one of their major components. Gurjenene falls under the sesquiterpene hydrocarbon group that is known to contribute to the wood fragrant aroma in gaharu essential oil. Therefore, it can be confirmed that microwave pretreatment did not destroy the original aroma of gaharu essential oil. In addition, the amount of gurjenene in the sample with microwave pretreatment was found to behigher than the non-pretreated sample, thus the essential oil produced from the pretreated sample had a sweeter wood odor compared to the non-pretreated one.

Exposing the gaharu to microwave pretreatment increased the purity of most compounds including, (+)Epi-bicyclosesquiphellandrene, gurjunene, $a$-farnese, estragole, guaiene, valencene, spathulenol, $\alpha$-cubebene and (-)-Spathulenol. A similar study using Nigella sativa L. seeds showed that microwave pretreatment was an effective factor in oil quality [19-21]. However, for certain chemical compounds such as a-panasinsene, exposure to a high power microwave energy of $800 \mathrm{~W}$ had reduced its percentage of purity. This is due to the degradation or loss of material that occur when the temperature or pressure inside the microwave is high. 
Table 2. Chemical composition for without pretreatment and microwave pretreatment $(3 \mathrm{~min})$ at $30 \mathrm{~h}$ of hydrodistillation processing time

\begin{tabular}{|c|c|c|c|c|c|c|}
\hline \multirow{2}{*}{ Chemical compound } & \multicolumn{3}{|c|}{$\begin{array}{c}\text { Untreated gaharu essential oil at } 30 \mathrm{~h} \\
\text { hydrodistillation extraction }\end{array}$} & \multicolumn{3}{|c|}{$\begin{array}{l}\text { Microwave pre-treated gaharu essential } \\
\text { oil at } 30 \mathrm{~h} \text { hydrodistillation extraction }\end{array}$} \\
\hline & $\begin{array}{l}\text { Retention time } \\
(\mathrm{min})\end{array}$ & $\begin{array}{l}\text { Amount } \\
(\%)\end{array}$ & $\begin{array}{c}\text { Purity } \\
(\%)\end{array}$ & $\begin{array}{l}\text { Retention time } \\
(\mathrm{min})\end{array}$ & $\begin{array}{l}\text { Amount } \\
(\%)\end{array}$ & $\begin{array}{l}\text { Purity } \\
(\%)\end{array}$ \\
\hline a-Panasinsene & 17.725 & 0.259 & 45 & 18.124 & 0.021 & 19 \\
\hline Gurjunene & 19.523 & 0.186 & 37 & 19.495 & 0.541 & 54 \\
\hline a-Farnesene & 22.828 & 0.162 & 33 & 22.611 & 0.261 & 42 \\
\hline Estragole & 8.1349 & 0.154 & 49 & 8.1206 & 0.298 & 69 \\
\hline \multirow{2}{*}{ Guaiene } & 19.518 & 0.018 & 10 & 12.911 & 0.306 & 63 \\
\hline & & & & 25.852 & 0.158 & 36 \\
\hline a-Guaiene & 12.957 & 0.110 & 38 & - & - & - \\
\hline Verrucarol & 31.104 & 0.092 & 25 & 30.634 & 0.371 & 33 \\
\hline Aromadendrene & 18.475 & 0.056 & 23 & - & - & - \\
\hline Valencene & 21.325 & 0.047 & 20 & 21.219 & 0.133 & 35 \\
\hline Caryophllene & - & - & - & 25.852 & 0.055 & 17 \\
\hline a-Caryophllene & 14.619 & 0.046 & 21 & 21.8 & 0.066 & 12 \\
\hline Spathulenol & 30.916 & 0.043 & 12 & 22.603 & 0.318 & 43 \\
\hline (-)-Spathulenol & 22.173 & 0.026 & 10 & 22.603 & 0.383 & 37 \\
\hline$\beta$-Selinene & 19.660 & 0.032 & 11 & - & - & - \\
\hline a-cubebene & 17.249 & 0.028 & 8 & 18.986 & 0.044 & 25 \\
\hline Cis-Limonenen oxide & 15.461 & 0.014 & 21 & 19.927 & 0.095 & 22 \\
\hline a-Vatirenene & 22.750 & 0.026 & 12 & - & - & - \\
\hline a-Phellandrene & 24.978 & 0.022 & 10 & - & - & - \\
\hline (+)-Epi-bicyclosesquiphellandrene & 18.241 & 0.017 & 7.9 & 18.361 & 0.092 & 27 \\
\hline Germacrene & 19.024 & 0.02 & 25 & - & - & - \\
\hline Citronellyl propionate & - & - & - & 19.347 & 0.033 & 11 \\
\hline$\beta$-Cadinene & - & - & - & 18.366 & 0.031 & 5.3 \\
\hline Citronellal & - & - & - & 16.026 & 0.03 & 13 \\
\hline Squalene & 19.711 & 0.014 & 21 & - & - & - \\
\hline Humulane-1,6-dien-3-ol & 18.552 & 0.012 & 7.9 & - & - & - \\
\hline c-Elemene & - & - & - & 19.317 & 0.026 & 10 \\
\hline Aristolene & - & - & - & 22.640 & 0.075 & 16 \\
\hline
\end{tabular}

Thus, to avoid losing valuable chemical compounds, the power of the microwave energy should be reduced and studied.

\section{- CONCLUSION}

This study highlights the effect of microwave pretreatment on gaharu essential oil using the hydrodistillation method as well as the effect of microwave processing and hydrodistillation time on gaharu oil yield. From the results, several main findings can be deduced. The oil yield values extracted by microwave pretreated samples were higher than those obtained by the non-pretreated samples. The longest microwave pretreatment time increased the exposure time to the wall structure of gaharu causing it to break down. Microwave penetrates directly into biomass substrate and generate heat from within, therefore enhancing the extraction efficiency of the components contained in the plant bodies. In conclusion, microwave pretreatment produces high quality essential oil with a higher amount of chemical compositions. This technique can be used as a desirable pretreatment 
method prior to extraction. This study gives an alternative to the gaharu essential oil manufacturers to utilize thelowgrade gaharu to obtain a more valuable product.

\section{- ACKNOWLEDGMENTS}

The authors would like to thank the Faculty of Chemical Engineering, UiTM and Universiti Teknologi MARA for providing the research facilities.

\section{- REFERENCES}

[1] Naef, R., 2011, The volatile and semi-volatile constituents of agarwood, the infected heartwood of Aquilaria species: A review, Flavour Fragrance J., 26 (2), 73-87.

[2] Ismail, N., Ali, N.A.M., Jamil, M., Rahiman, M.H.F., Tajuddin, S.N., and Taib, M.N., 2015, A Review on Agarwood and Its Quality Determination, Jurnal Teknologi, 68 (1), 37-42.

[3] Ali, B., Al-Wabel, N., Shams, S., Ahamad, A., Khan, S.A., and Anwar, F., 2015, Essential oils used in aromatherapy: A systematic review, Asian Pac. J. Trop. Biomed., 5 (8), 601-611.

[4] Yusoff, N.A.M., Tajuddin, S.N., Hisyam, A., and Omar, N.A.M., 2015, Production of agarwood essential oil study on effectiveness pre-treatment technique of hydrodistillation extraction, BJRST, 5 (2), 62-69

[5] Barden, A., Anak, N.A., Mulliken, T., and Song, M., 2000, Heart of the Matter: Agarwood Use and Trade and CITES Implementation for Aquilaria malaccensis, TRAFFIC International, Cambridge, United Kingdom.

[6] Tan, C.S., Isa, N.M., Ismail, I., and Zainal, Z., 2019, Agarwood induction: Current developments and future perspectives, Front. Plant Sci., 10, 122.

[7] Rassem, H.H.A., Nour, A.H., and Yunus, R.M., 2016, Techniques for extraction of essential oils from plants: A review, Aust. J. Basic Appl. Sci., 10 (16), 117-127.

[8] Sulaiman, N., Idayu, M.I., Ramlan, A.Z., Fashya, M.N., Farahiyah, A.N.N., Mailina, J., and Azah, M.A.N., 2015, Effects of extraction methods on yield and chemical compounds of gaharu (Aquilaria malaccensis), J. Trop. For. Sci., 27 (3), 413-419.
[9] Uquiche, E., Jeréz, M., and Ortíz, J., 2008, Effect of pretreatment with microwaves on mechanical extraction yield and quality of vegetable oil from Chilean hazelnuts (Gevuina avellana Mol), Innovative Food Sci. Emerg. Technol., 9 (4), 495500.

[10] Wroniak, M., Rękas, A., Siger, A., and Janowicz, M., 2016, Microwave pretreatment effects on the changes in seeds microstructure, chemical composition and oxidative stability of rapeseed oil, LWT Food Sci. Technol., 68, 634-641.

[11] Hashim, Y.Z.H.Y., Ismail, N.I., and Abbas, P., 2014, Analysis of chemical compounds of agarwood oil from different species by gas chromatography mass spectrometry (GC-MS), IIUM Eng. J., 15 (1), 55-60.

[12] Chen, F., Mo, K., Zhang, Q., Fei., S., Zu, Y., and Yang, L., 2017, A novel approach for distillation of paeonol and simultaneous extraction of paeoniflorin by microwave irradiation using an ionic liquid solution as the reaction medium, Sep. Purif. Technol., $183,73-82$.

[13] Xu, W., Zhu, G., Song, C., Hu, S., and Li, Z., 2018, Optimization of microwave vacuum drying and pretreatment methods for Polygonum cuspidatum, Math. Prob. Eng., 2018, 4967356.

[14] Yoswathana, N., 2013, Extraction of agarwood (Aquilaria crassna) oil by using supercritical carbon dioxide extraction and enzyme pretreatment on hydrodistillation, J. Food Agric. Environ., 11 (2), 1055-1059.

[15] Azadmard-Damirchi, S., Alirezalu, K., and Achachlouei, B.F., 2011, Microwave pretreatment of seeds to extract high quality vegetable oil, World Acad. Sci. Eng. Technol., 5 (9), 508-511.

[16] Fadzil, A.H.M., Hamid, K.H.K., Rodhi, M.N.M., and Kamaruddin, L.M., 2013, Extraction of essential oil from biologically inoculated agarwood, 2013 IEEE Business Engineering and Industrial Applications Colloquium (BEIAC), 889-892.

[17] Azadmard-Damirchi, S., Habibi-Nodeh, F., Hesari, J., Nemati, M., and Achachlouei, B.F., 2010, Effect of pretreatment with microwaves on oxidative 
stability and nutraceuticals content of oil from rapeseed, Food Chem., 121 (4), 1211-1215.

[18] Yang, M., Huang, F., Liu, C., Zheng, C., Zhou, Q., and Wang, H., 2013, Influence of microwave treatment of rapeseed on minor components content and oxidative stability of oil, Food Bioprocess Technol., 6, 3206-3216.

[19] Mazaheri, Y., Torbati, M., Azadmard-Damirchi, S., and Savage, G.P., 2019, Effect of roasting and microwave pre-treatments of Nigella sativa L. seeds on lipase activity and the quality of the oil, Food Chem., 274, 480-486.
[20] Fathi-Achachlouei, B., Azadmard-Damirchi, S., Zahedi, Y., and Shaddel, R., 2019, Microwave pretreatment as a promising strategy for increment of nutraceutical content and extraction yield of oil from milk thistle seed, Ind. Crops Prod., 128, 527533.

[21] Bakhshabadi, H., Mirzaei, H., Ghodsvali, A., Jafari, S.M., Ziaiifar, A.M., and Farzaneh, V., 2017, The effect of microwave pretreatment on some physicochemical properties and bioactivity of Black cumin seed's oil, Ind. Crops Prod., 97, 1-9. 